\title{
The start up as a phase of architectural design process
}

\author{
Iara Sousa Castro ${ }^{\mathrm{a}}$, Francisco de Paula Antunes Lima ${ }^{\mathrm{b}}$ and Francisco José de Castro Moura Duarte ${ }^{\mathrm{c}}$ \\ ${ }^{a}$ School of Design at the Federal University of the State of Minas Gerais; \\ ${ }^{b}$ Department of Production Engineering at the Federal University of Minas Gerais \\ ${ }^{c}$ Program of Production Engineering at the Federal University of Rio de Janeiro
}

\begin{abstract}
Alterations made in the architectural design can be considered as a continuous process, from its conception to the moment a built environment is already in use. This article focuses on the "moving phase", which is the initial moment of the environment occupation and the start-up of services. It aims to show that the continuity of ergonomics interventions during the "moving phase" or start up may reveal the built environment inadequacies; clearly showing needs not met by the design and allowing making instant decisions to solve non-foreseen problems. The results have revealed some lessons experienced by users during a critical stage not usually included in the design process.
\end{abstract}

Keywords: architectural design process; moving phase, use of a built environment; ergonomics analysis of work

\section{Introduction}

The post occupation evaluation - POE [9] has been recommended to improve the architectural design process, by allowing returning experience after the work delivery. By means of users' satisfaction evaluation and the analysis of detected problems, proposals for corrective actions are offered to future designs. However, the POE is not immediately carried out after the work delivery, being recommended to wait a certain time after the construction completion and occupation by users [8] so that situation is settled or put up. The objective of this article is to show that the experience in the beginning of occupation - called the moving phase or start up - is sui generis and brings a specific contribution to the design process. After a few months, the analyzed situation will not be the same from the time that space was made available to users. Users-environment relationships, including the physical-social context, are dynamic and the users' needs regarding space follow those needs, eventually leading to changes of the initial design and of the asbuilt. Thus the relative usage settling includes transformation and adaptation processes that may prevent the recovery of the moving phase experience.

As conception ergonomics has been showing, interventions during the design phase, designing, execution and utilization are not inactive steps. Alterations in the architectural design have been noticed during the life cycle of a built space, during all posterior phases after its conception: during construction, "execution phases or installation" [5], which only ends in the as-built, after all subsequent space transformations and adaptations. Those design alterations may be motivated by designers, executors or entrepreneurs, inspectors and also, by users. Each of those agents may interfere in the design evolution, with more or less power and according to the architectural design process they take part in.

The moving phase or start up is an evolution and transformation moment of design when the user is deeply involved once experts are no longer present: neither designers nor ergonomists. At that moment, POEs have not been started yet and ergonomics analyses have not been demanded upon request. Therefore, systematic analysis are not made and the moving is not followed, even though the start-up is known as an unstable period and potentially fertile to provide important information to be explored in the 
design. Precisely for its transitory characteristics, the moving phase offers an opportunity of continuation to the space creation process, validating solutions proposed by designers or emphasizing inadequacies and also adjusting a built environment, within the possibilities, with solutions developed by users according to their needs.

However little is known on the beginning of the space appropriation and activity processes. Appropriation can be understood through the moving attitude which is a true spatial practice when each individual is inserted in a space [6]. By individually occupying a certain space, the user tends to modify it in order to adjust it to his/her own needs. Despite all the possibilities of identifying difficulties, not foreseen in design, are already recognized during the start-up moment, little is known about the appropriation process by users.

Even in more successful designs it is natural that users face certain difficulties not foreseen by designers. In the face of those difficulties, occupants initialize subjective processes and adaptation strategies that may cause to lodge or overcome difficulties under inappropriate conditions. Those subjective processes and strategies of users lead to making instant decisions to solve problems originated from past decisions that have materialized in that design. Thus, the necessities non-fully met by the design encourage the continuation of the design by users, without the presence of an expert.

During the start-up, users face the relative limits of the transformation of a situation and even its irreversibility. Trying to deal with those difficulties, users seek solutions inspired in their past experiences. Therefore, the objective of this article is to show that the continuity of the ergonomics interventions during start-up can support the experience development.

An extract of a case study from the doctorate thesis by one of the authors [2], that approaches the waiting room of a French day-hospital ward for patients holding the HIV (human immunodeficiency virus), is intended to illustrate the objective of this article. The WEA -Work Ergonomics Analysis was made [7] which indicated some Situations of Characteristic Actions - SCAs [4] that allowed extracting some lessons to the experience development.

\section{Case Study: HIV day-hospital waiting room}

This HIV day-hospital is a sector already existing since 1992, with an area of $149 \mathrm{~m}^{2}$, but it has presented a significant growth in the number of patients along the years, making it necessary to improve its infrastructure. The hospital has made available a new area of $279 \mathrm{~m}^{2}$ to relocate the dayhospital.

An architectural design was made involving a team of an architect, an ergonomist, and designer experts. They have worked together during the diagnose and pre-design phases.

\subsection{The before-design space}

Before design this day-hospital did not count on a waiting room. There was a corridor to access all the sector rooms and some characteristic action situations happened inside it, such as: arrival, waiting, and setting of new appointments /exams and the feeding of patients; transit of people, meals and nursery trolleys; and also the space cleaning.

That corridor has previously been a space of 37 $\mathrm{m}^{2}$, long, narrow and confined. There were no windows to provide ventilation and natural lighting and the transit space for nursery and meal trolleys between furniture and people was restricted.

Patients were sat on sofas and chairs, close and in front of the others, once there was no other solution for that space. That embarrassed the ones willing to maintain their own confidentiality.

It was possible to establish a reciprocal control relation between patients and health agents, since the room doors were kept opened providing the omnipresence principle [1]. A positive aspect was that the visual control by health agents on patients favored to observe their conditions: if they were restless, drawn, depressed or feeling well. A negative aspect was that patients could observe others been treated: even when doors were shut, patients could hear what was said in other rooms, with no privacy. Thus, each patient knew that other people could also hear them while they were treated.

Patients' nutrition was individually and sequentially carried out, which means, one patient after the other, once there were only a small table and a chair for this purpose. The other patients waiting for their turn to eat stayed in the same environment. In order to provide more privacy to the patient having his/her meal, that table was visually protected by a bookcase packed full of information and education 
brochures on diseases. However the noise of cutlery and the smell of food spread all over the environment.

In the face of it, a waiting room design concept was elaborated for the day-hospital new facility. It was based on three guidelines:

a) provoking contact among patients so they could exchange life experiences;

b) providing privacy in setting appointments, once it is many times an embarrassing moment for a patient who needs to solve doubts or say intimate or personal things in front of other people;

c) favoring the control by health agents of patients' access, staying or flow.

\subsection{The after-design space}

The new HIV day-hospital then won a $22 \mathrm{~m}^{2}$ waiting room taking patients out of the corridor and the direct contact with the treatment space doors. That has improved privacy related to what happened during other patients' treatments.

The environment was no longer confined and received natural ventilation and lighting. Color and texture composition provided a differentiated atmosphere to the hospital environment.

In the Center of the room, there was a metallic structure isolating and protecting patients sitting at tables from the transit of people and cleaningmaterial, nursery and food trolleys.

There were also differentiated corners which allowed patients to vary their position when room was not crowded. In addition to that, in this room there were bookcases with reading brochures, a drinking fountain and a bar-type kitchen for communal meals.

Visual control by the agents on patients has decreased because the waiting room was not directly connected to the other rooms. Thus, it was crucial that all patients rang the doorbell to announce their arrival and be immediately helped.

\section{Results of the ergonomics analysis during the "moving phase" or start up}

Ergonomic analysis made in the "moving phase" or start up, which means, in the beginning of the space occupation and services has taught some lessons as mentioned bellow:

3.1. An immediate comparison of a new environment with the environment previously occupied brings awareness of positive and negative aspects on what was incorporated in relation to what was experienced

The first positive impressions proved the health agents' satisfaction when receiving patients in a waiting room with infrastructure to help treat and feed them. Some patients also observed that besides being beautiful, the waiting room was cozier than the former waiting corridor. It was also observed that patients were no longer close to treatment room doors and could not listen to conversations during other patients' treatments.

The first negative impressions originated from patients that hoped they would have more confidentiality in the new day-hospital, but the waiting room was proposed contrarily to what they expected by trying to promote contact among people.

The collective eating experience was incorporated to the final design to promote more contact among people during meal time. However, several patients preferred to eat inside their rooms or in the treatment spaces where they could not be seen.

By bringing food prepared in the general kitchen of the hospital, the reception clerk had difficulty moving the meal trolley among patients because of the restricted space and layout of tables.

Regarding cleaning, a specific material easily caused shoe marks on the floor. The agent responsible for cleaning had as strategy to accomplish it during lunch time what made the users to strategically use a disposable towel to slide over the floor, when moving around during cleaning time.

Awareness of positive and negative aspects in the new built environment, being incorporated to the new use experiences were based on what was experienced in the day-hospital before the design and served as reference to the design concept.

3.2. When all actors involved with design believe in the benefits of repeating solutions from similar nature environments

The ergonomist has brought the concept of contact, implicit in the proposal of the general hospital's garden already known by the agents, for the architect to make it come true in the design. Introduction of this contact concept aimed to humanize services and minimize conflicts existing in the waiting room before the design.

Even though the any- specialty-day-hospital proposal itself already represented the humanization 
of the hospital sector, by offering the advantage of treatments during the day and allowing the patients to return home, patients also need to be given conditions that are coherent to this humanization trend of services and to their own conscious and mobile situation [3]. Thus, an environment of different uses and that allowed patient to have an active behavior was created.

The day-hospital design architect and ergonomist have proposed the concept of a room allowing contact among patients, where they could exchange experiences and enjoy a bar-type kitchen. This idea has originated from a hospital sector general trend that had already been successful in that hospital, with a unique same cafeteria and garden common to all hospital sectors.

Despite the fact that this waiting room may cause new feelings in users from stimulus not existing before the design, patients have not changed their behavior related to their condition as patients. The stimulus of natural lighting, color composition from the environment's different elements and the smell of coffee coming from the kitchen creates a smoother ambience that positively influences the users' feelings; though it was not enough to make them feel comfortable to talk to each other. They still prefer to wait alone inside the treatment booths or rooms instead of waiting to be helped in the company of other patients because of prejudice against this disease. Patients feared to be seen by people they know or, even people they could meet in different future situations.

Besides that, while patients waited to be helped, gathered in the waiting room, the need of each patient to avoid being observed by others was noticed; not only for fearing to be recognized outside the HIV day-hospital and pointed as ill or holding the virus but also for feeling embarrassed by the way this disease was visually revealed in each of them.

It was observed that an inexistent experience of a waiting room gathering patients in the day-hospital before the design has caused a conflict between users and the waiting room new environment, even though the designers' proposal was successful in other hospital sectors.

3.3. An user tends to give instant solutions to conflicts, based on his/her experiences, even when he/she knows that solution means returning to what has not worked well before.
In the face of several problems, the users' experience may help them to evaluate which is worst and which needs a prompt solution even when that solution means to cause another type of problem. When users already know the way a problem may be revealed, they promptly make decisions being aware of their consequences.

One example that well illustrates this circumstance is the solution given in the moving day by nurses to solve three problems: one in the preparation room, another for the dynamics of the nurses' activities and a third one for the nurses' actions.

In the preparation room, the counter planned for preparations was under-dimensioned and occupied by a computer for administrative tasks. Therefore, nurses began to use the nursery trolleys to carry out preparations. However, the positioning of trolleys in the preparation room negatively interfered with the agents' flow inside that environment, in addition to deny the possibility of placing trolleys under the counter as designed due to the incompatibility of trolley and counter heights.

Because of that, a corner reserved for setting appointments and exams, strategically located in the day-hospital corridor, between the preparation room and the waiting room, was transformed into preparation spaces, specifically for collecting blood. Trolleys placed under the counter and other instruments did not allow a multiple use of space compatible with the setting of appointments.

Nurses have so reintroduced the setting of appointments in the waiting room, according to what was done in the corridor previously to design. This new environment was considered more comfortable than the waiting corridor, once the appointment book that previously lay on the nurse's lap was then, after design, put on a table. Privacy conflict during the appointment settings, however, continued to exist because of this alteration. In both waiting environments (before and after design), communication represented a cost of cognitive and affective nature to the individuals involved, which influenced the social activity [6]. Taking as priority a problem solution by causing another problem originated from the nurses' own experiences.

\section{Conclusion}

The moving phase or start up is a critical stage, experienced by users and, usually, not included in the process of conceiving and transforming a built environment. During this phase, capitalization of the 
use experience provides information that may get lost with time, before being incorporated to the design process, as well as it is possible to observe users' feelings and experiences during their activities through the work spaces.

The result of the Ergonomics Analysis of Work in this HIV day-hospital indicates that the presence of designers during the moving phase or start up would favor to solve problems and continue the social construction developed during design process, which would benefit users as well as designers. The start up would represent for users to consolidate the comprehension on the basis that have guided the design. For designers, it could help them to rethink a way of leading future designs, being so a rich and singular source of reference for the architectural design process in similar future situations.

\section{References}

[1] Bentham, J.; Miller, J. A.1.; Perrot, M.; Werrett, S. (2008) O panóptico . Belo Horizonte: Autêntica.

[2] Castro, I. S. (2010). A capitalização da experiência do uso do ambiente construído: contribuições da Avaliação PósOcupação e da Análise Ergonômica do Trabalho. Estudo de caso realizado em um hospital-dia VIH. (Tese de Doutorado em Arquitetura). Rio de Janeiro: Escola de Arquitetura da Universidade Federal do Rio de Janeiro. Retrieved august, 17, 2010, from http://www.fau.ufrj.br/prolugar/arq pdf/teses/teseIaraCASTRO.pdf.

[3] Cavalcanti, P.B.; Azevedo, G. A. N.; Ely, V. H. M. B. (2009) Indicadores de qualidade ambiental para hospitais-dia. In Ambiente Construído. 9, 2, 73-86.

[4] Daniellou, F. (1999) Le statut de la pratique et des connaissances dans l'intervention ergonomique de conception. Bordeaux: ISPED

[5] Duarte, F. J. C. M. Cordeiro, C. V. C. (2000). A etapa de execução da obra: um momento de decisões. In: Revista Produção, Número Especial, 5-28.

[6] Fischer, G.-N. (1981). La psychologie de 1'espace. Paris: Presses Universitaires de France.

[7] Guérin, F.; Laville, A.; Daniellou, F.; Duraffourg, J.; Kerguelen, A. (2001) Comprendre le travail pour le transformer. Paris: ANACT.

[8] Ornstein, S. W.; Roméro, M. (Col.). Avaliação Pós-Ocupação do Ambiente Construído. São Paulo: Nobel, 1992.

[9] Preiser, W.; Rabinowitz, H.; White, E. Post-Occupancy Evaluation. New York: Van Nostrand Reinhold, 1988. 1988 p.

Research sponsored by FAPEMIG - Research Supporting

Fundation of the State of Minas 